\title{
Breast animation deformity
}

\author{
Diana Lydia Dyrberg ${ }^{1}$, Camilla Bille ${ }^{2}$, Gudjon Leifur Gunnarsson ${ }^{3}$, Tove Faber Frandsen ${ }^{4}$, \\ C. Andrew Salzberg ${ }^{5}$, Jens Ahm Sørensen ${ }^{2}$, Jørn Bo Thomsen ${ }^{1}$ \\ ${ }^{1}$ Department of Plastic Surgery, Odense University Hospital, Odense and Lillebaelt Hospital, Vejle; ${ }^{2}$ Department of Plastic Surgery, Odense \\ University Hospital, Odense, Denmark; ${ }^{3}$ Department of Plastic Surgery, Telemark Hospital, Skien, Norway; ${ }^{4}$ Videncentret, Odense University \\ Hospital, Odense, Denmark; ${ }^{5}$ Department of Plastic and Reconstructive Surgery, Mount Sinai Hospital, New York, NY, USA
}

Breast animation deformity (BAD) has been reported to occur after submuscular implant placement following breast augmentation and immediate breast reconstruction. Despite its apparent impact on patients' quality of life, BAD has only recently become a topic of general concern. Its incidence and etiology have yet to be established. The aim of this systematic review was to identify papers that clearly defined and classified BAD and described how the degree of animation was assessed. We performed a search in PubMed and Embase. Studies meeting the inclusion criteria that described BAD after implant-based breast augmentation or immediate breast reconstruction were included. After screening 866 publications, four studies were included: three describing BAD after breast augmentation and one describing $B A D$ after immediate breast reconstruction. The median percentage of patients with some degree of BAD was $58 \%$. The highest percentages were found in patients operated on using the Regnault technique or the dual-plane technique (73\%-78\%). The lowest percentages were found following the dual-plane muscle-splitting technique (30\%) and the triple-plane technique (33\%). We found no studies meeting the inclusion criteria that analyzed BAD after prepectoral implant placement. This review of the current literature suggests that the degree of BAD is proportional to the degree of muscle involvement. Evidence is scarce, and the phenomenon seems to be underreported. Future comparative studies are warranted.

Keywords Treatment outcome / Breast reconstruction / Breast implant / Mammaplasty
Correspondence: Jørn Bo Thomsen Department of Plastic Surgery, Odense University Hospital and Lillebaelt Hospital, Vejle, Sdr Boulevard 29, 5000 Odense C, Denmark Tel: $+45-29270029$ Fax: $+45-65413038$ E-mail: joern.bo.thomsen@rsyd.dk

Received: 16 May 2018 Revised: 31 Jul 2018 Accepted: 27 Aug 2018

pISSN: 2234-6163 • elSSN: 2234-6171 • https://doi.org/10.5999/aps.2018.00479• Arch Plast Surg 2019;46:7-15

\section{INTRODUCTION}

Breast animation deformity $(\mathrm{BAD})$ is a condition in which the shape of the augmented or reconstructed breast changes or is distorted during contraction of the major pectoralis muscle [1]. The distortion may lead to varying degrees of widened cleavage, and upward or superolateral implant malposition and asymmetry $[2,3]$. BAD has been reported to occur following submuscular implant placement in breast augmentation procedures and frequently after immediate breast reconstruction [4-6].

The most commonly employed pocket planes for augmentation mammaplasty are prepectoral (subfascial or subglandular) and partial subpectoral (dual or triple-plane) (Fig. 1). The opposite tends to apply to breast reconstruction, for which the most commonly employed pocket is subpectoral or submuscular. The reason for this is to place the implants in a space with a vascularized cover due to concerns about post-mastectomy skin breakdown [7]. The advantages of subpectoral or submuscular 
placement are reduced rippling and implant visibility, as well as a lower incidence of capsular contracture. Furthermore, it facilitates mammography $[8,9]$.

$\mathrm{BAD}$ has recently received attention in the literature as a condition that affects especially active women, seems to be significantly more common in patients with subpectorally-placed implants, and appears to be even more common in patients who have undergone breast reconstruction procedures [10]. Spear et al. [6] reported that up to $53 \%$ of patients experienced some degree of $\mathrm{BAD}$ following subpectoral implant placement after dual-plane augmentation, whereas Nigro and Blanchet [10] reported that $75.6 \%$ of patients experienced some degree of $\mathrm{BAD}$ after reconstruction. $\mathrm{BAD}$ is not only a cosmetic problem, but also a functional problem, as it can lead to muscle twitching, pain, and possibly impaired shoulder function in physically active women, which may ultimately affect their quality of life $[2,5]$. Furthermore, BAD may be associated with a longer postoperative recovery time, as more pain has been reported in patients who underwent subpectoral reconstruction and augmentation than in their counterparts who underwent prepectoral reconstruction and augmentation $[11,12]$.
Various methods of treating $\mathrm{BAD}$ have been investigated, including neuromodulating injections into the pectoralis major muscle [13], selective nerve transection [14], reoperation with a muscle-splitting technique [15], and repositioning of the implant to a prepectoral position with or without fat grafting [16].

Prepectoral implant placement is gaining wider acceptance worldwide; however, this implies less tissue coverage, leaving the implant more visible, especially following immediate breast reconstruction and to a lesser degree following breast augmentation. Furthermore, the incidence of capsular contracture has been reported to be higher following prepectoral implant placement [17]. The use of biological meshes has been described as a way to reduce implant visibility and $\mathrm{BAD}$; however, these materials cannot be expected to replace either the muscle volume or coverage of the implant [11].

Numerous papers have mentioned $\mathrm{BAD}$ and concluded that it is not a significant problem. However, it is much rarer for papers to define $\mathrm{BAD}$, to classify it, or to describe how the degree of $\mathrm{BAD}$ was assessed $[3,14,16,18]$.

The primary aim of this systematic review was to identify and select papers that clearly defined and classified $\mathrm{BAD}$ and de-

\section{Fig. 1. Illustrations of implant planes}

(A) Images showing four different types of implant placement from a side view: (a) subpectoral, (b) dual-plane, (c) triple-plane, and (d) prepectoral. (B) Images showing three different types of submuscular implant placement from a frontal view: (a) muscle-splitting I, (b) muscle splitting II (Regnault technique), and (c) triple plane.
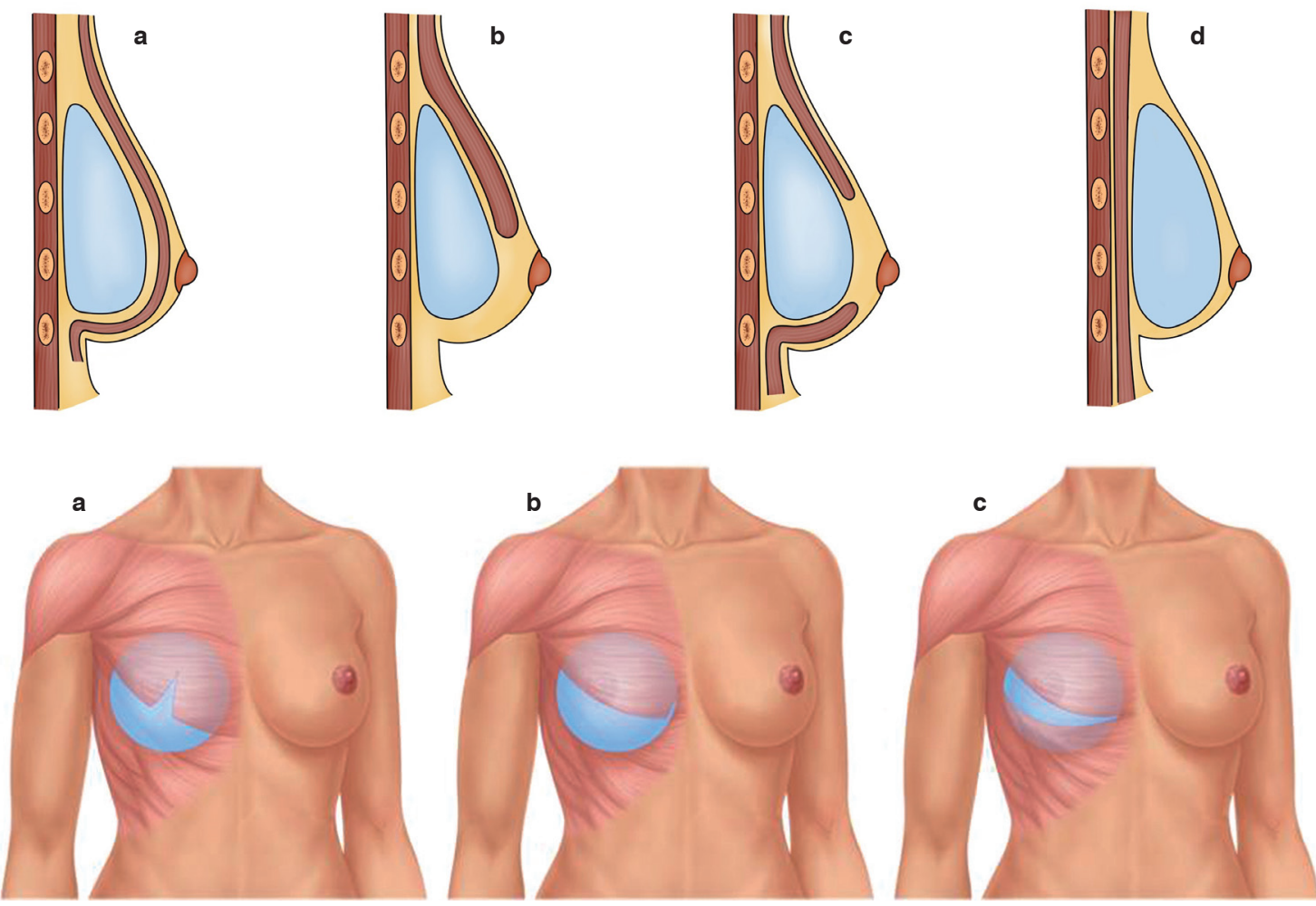
scribed how the degree of animation was assessed. Additionally, by utilizing these selected papers, this review aimed to estimate the incidence of this condition following breast augmentation and breast reconstruction. The third aim was to synthesize existing knowledge about $\mathrm{BAD}$ and its current classification.

\section{METHODS}

\section{Systematic literature search}

We performed a systematic search in May 2017 in the following electronic bibliographic databases: PubMed (National Library of Medicine, NLM), Embase Classic (Ovid), and Embase (Ovid). We validated and tested the PubMed search strategy shown below and translated the search for use in Embase, adjusting the controlled vocabulary as applicable: (implant OR implantation) AND (distortion OR distortions OR dislocation OR dislocations) OR ((animation OR animations OR dynamic) AND (excessive OR distortion OR distortions OR deformity OR deformities)) OR ((muscle OR muscles) AND (elevation OR elevations OR contraction OR contractions OR flexion)) OR (jumping OR rippling OR ripple OR animated) AND (mammaplasty OR Mammaplasties OR Mammoplasties OR mastoplasty OR mastoplasties) OR (breast OR breasts OR

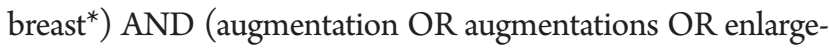
ment OR enlargements OR enhancement OR enhancements OR implant OR implants OR implantation OR implantations OR reconstruction $\mathrm{OR}$ reconstructions $\mathrm{OR}$ reconstructive $\mathrm{OR}$ surgery OR surgeries OR operation OR operations OR prosthesis OR prostheses).

The searches were conducted with no date or language limits. The databases were searched from the inception date forward. The reference lists of the selected papers were subsequently reviewed for additional papers. The Preferred Reporting Items for Systematic Reviews and Meta-Analysis (PRISMA) flowchart of the selection is presented in Fig. 2. The complete search histories are available in Supplemental Table 1.

\section{Inclusion criteria}

We used the PRISMA guidelines for this review [19]. The titles of the papers identified by the search string above were screened for whether they included the words "BAD" and synonyms, "implant-based breast augmentation," or "immediate breast reconstruction." The abstracts were then reviewed and screened for relevant data about women undergoing implant-based breast augmentation or immediate breast reconstruction and a relevant description of BAD. Full-text papers were retrieved according to

\section{Fig. 2. PRISMA flowchart}

This flowchart shows the selection process after our literature search. PRISMA, Preferred Reporting Items for Systematic Reviews and Meta-Anal-

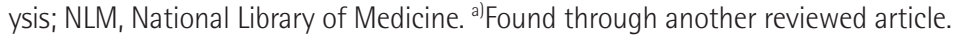
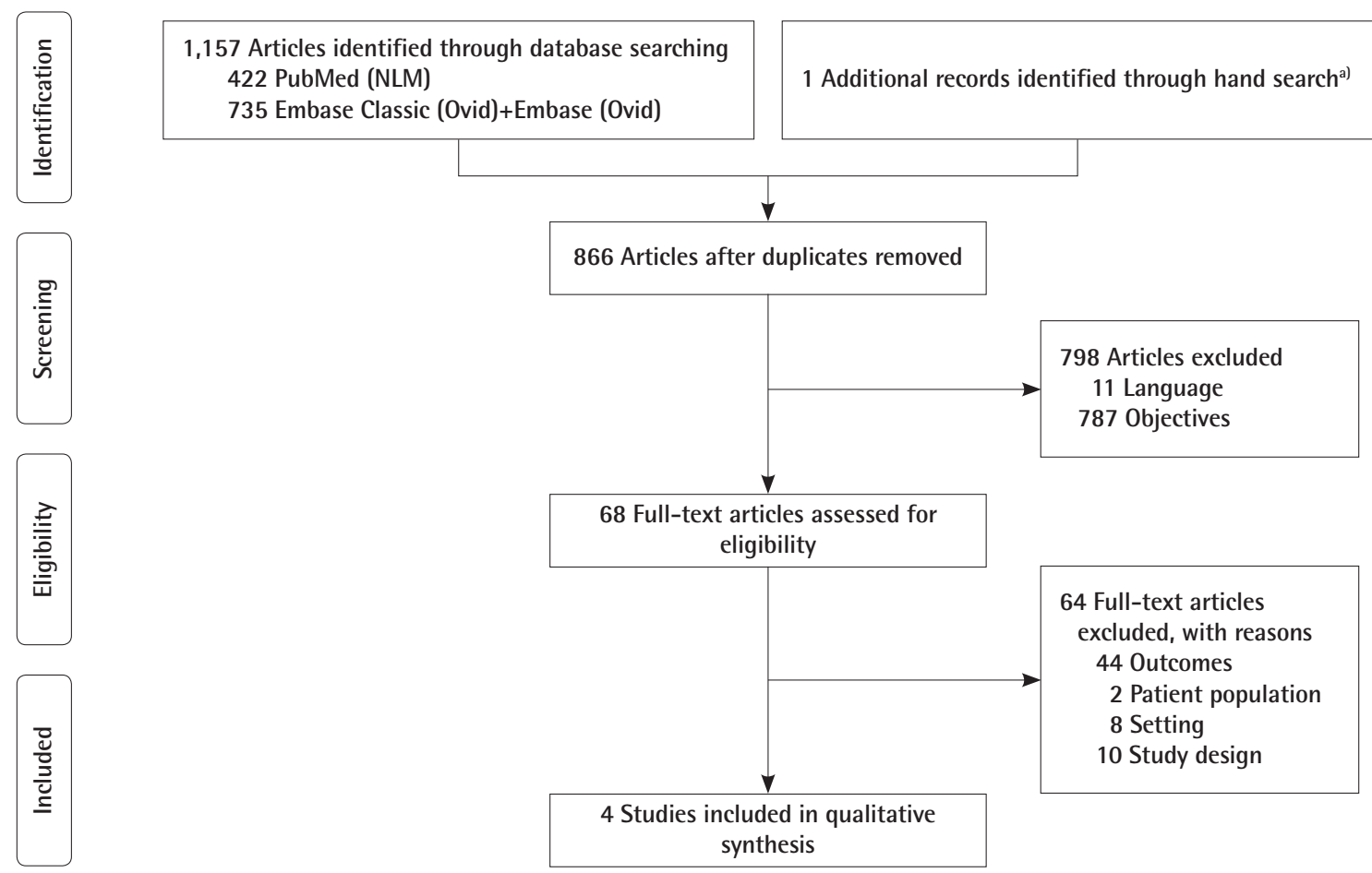

68 Full-text articles assessed for eligibility

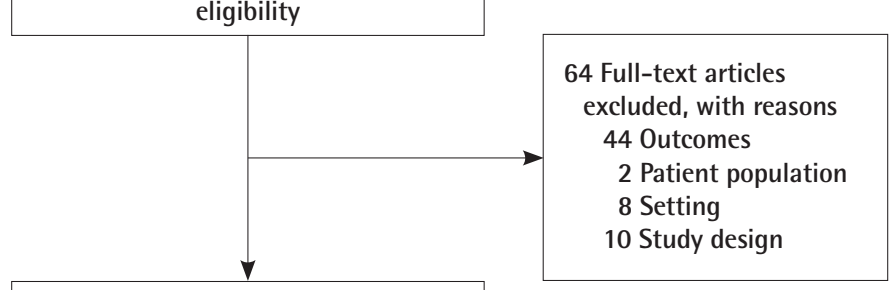

4 Studies included in qualitative synthesis 
the selected abstracts and read and screened by two authors (JBT and DLD) independently of each other to determine which articles should be included in this review. We included all studies describing implant-based breast augmentation or immediate breast reconstruction and $\mathrm{BAD}$, in which $\mathrm{BAD}$ was clearly defined.

\section{Data extraction}

The included studies were reviewed using a descriptive checklist including the first author, year of publication, type of study, number of participants, method of data collection, and a description of the person who collected the data, the time of follow-up, and outcome variables (Table 1).

The quality of the individual studies was then evaluated with regard to: description of the study sample, participation rate, description of the surgical technique, follow-up, assessment of $\mathrm{BAD}$, definition/classification of $\mathrm{BAD}$, or whether the definition of $\mathrm{BAD}$ was reproducible (Table 2). The different definitions of $\mathrm{BAD}$ are presented in Table 3 and the reported incidence rates of $\mathrm{BAD}$ are shown in Table 4.

\section{Review process and interpretation of data}

Two of the authors reviewed the papers and extracted the information separately, blind to each other's findings. Their findings were then compared. In case of disagreement a third author was consulted. The review was registered in the PROSPERO database (CRD42017068154).

\section{RESULTS}

\section{Number of articles}

We retrieved 1,158 articles, which was reduced to 866 after removing duplicates. These 866 articles were reviewed as described above, yielding only four papers that described women who underwent either implant-based breast augmentation or immediate breast reconstruction in which the incidence of $\mathrm{BAD}$ was described and clearly defined $[1,6,10,20]$.

We found several studies describing $\mathrm{BAD}$ that were not included. These studies were excluded for the following three reasons: no clear definition of $\operatorname{BAD}[2,5,11,14,21-27]$, revision surgery $[3,15,16,28-30]$, and the absence of data regarding $B A D$ in the results section [18]. The selection process is presented in the PRISMA flowchart in Fig. 2.

\section{Study design, participants, and method}

The included papers were published from 2004 to 2017. Two were conducted in Italy and two in the United States. The de-

\section{Table 1. Descriptive checklist}

\begin{tabular}{|c|c|c|c|c|c|c|c|}
\hline Author (year) & Country & Type of study & $\begin{array}{c}\text { No. of } \\
\text { participants }\end{array}$ & $\begin{array}{l}\text { Method of data } \\
\text { collection }\end{array}$ & Data assessors & $\begin{array}{l}\text { Duration of } \\
\text { follow-up } \\
\text { (mo) }\end{array}$ & Outcome variable \\
\hline $\begin{array}{l}\text { Pelle-Ceravolo } \\
\text { (2004) [1] }\end{array}$ & Italy & Retrospective & $348 / 580^{a)}$ & $\begin{array}{l}\text { Physical exam, } 6 \text { judgements } \\
\text { for each patient }\end{array}$ & Surgeon, nurse, patient & 6 & BAD \\
\hline $\begin{array}{l}\text { Spear } \\
\text { (2009) [6] }\end{array}$ & USA & Case-series & $\begin{array}{l}40 / 40 \\
69 / 195\end{array}$ & $\begin{array}{l}\text { Photographs } \\
\text { Questionnaire (non-validated) }\end{array}$ & $\begin{array}{l}\text { Plastic surgery residents } \\
\text { Patient }\end{array}$ & 6 & $\begin{array}{l}\text { Incidence and severity } \\
\text { of } B A D \\
\text { Self-evaluation of BAD }\end{array}$ \\
\hline $\begin{array}{l}\text { Bracaglia } \\
\text { (2013) [20] }\end{array}$ & Italy & Retrospective & 524 & $\begin{array}{l}\text { Photographs } \\
\text { Physical exam) }\end{array}$ & Plastic surgeons & $6-180$ & $\mathrm{BAD}$ \\
\hline $\begin{array}{l}\text { Nigro } \\
\text { (2017) [10] }\end{array}$ & USA & Retrospective & $84 / 108$ & Questionnaire & Patient & $6-72$ & $\begin{array}{l}\text { BAD } \\
\text { Patient level of physical } \\
\text { activity }\end{array}$ \\
\hline
\end{tabular}

\section{Table 2. Quality checklist}

\begin{tabular}{|c|c|c|c|c|c|c|c|c|}
\hline Author (year) & $\begin{array}{c}\text { Clear } \\
\text { description } \\
\text { of study }\end{array}$ & $\begin{array}{l}\text { Participation } \\
\text { rate }\end{array}$ & $\begin{array}{l}\text { Description } \\
\text { of surgical } \\
\text { technique }\end{array}$ & $\begin{array}{l}\text { Similar } \\
\text { follow-up }\end{array}$ & $\begin{array}{l}\text { Competent } \\
\text { assessment } \\
\text { of BAD }\end{array}$ & $\begin{array}{c}\text { Definition of } \\
\text { BAD }\end{array}$ & $\begin{array}{c}\text { BAD } \\
\text { definition } \\
\text { reproducible? }\end{array}$ & Total score \\
\hline Pelle-Ceravolo (2004) [1] & Yes & Yes & Yes & No & Yes & Yes & No & $5 / 7$ \\
\hline Spear (2009) [6] & Yes & Yes & Yes & No & Yes & Yes & No & $5 / 7$ \\
\hline Bracaglia (2013) [20] & Yes & No & Yes & No & Yes & Yes & No & $4 / 7$ \\
\hline Nigro (2017) [10] & Yes & Yes & Yes & Yes & $\begin{array}{l}\text { Patient self- } \\
\text { assessment }\end{array}$ & Yes & No & $5 / 7$ \\
\hline
\end{tabular}


sign was retrospective in three studies and one was a case series. Three studies described BAD after breast augmentation and one following immediate breast reconstruction.

The number of participants ranged from 40 to 524 (Table 1). The age of the participants was clearly described in one of the four studies (median age, 50 years) [10]. Variation was present in the methods used to assess $\mathrm{BAD}$. In three of the four studies the degree of $\mathrm{BAD}$ was evaluated by the surgeons either through physical exams or by evaluating photographs of the patients using a grading scale $[1,6,20]$. Two of the four studies used a nonvalidated questionnaire for self-evaluation of the degree of $\mathrm{BAD}$ $[6,10]$. Nigro and Blanchet $[10]$ used the self-reported degree of $\mathrm{BAD}$ as the only outcome measure. The subjective grading scales used by each study were either 3-, 4-, or 10-point scales. One study converted the 10-point scale that they used to a 4-point scale in order to compare it with the study by Spear et al. The follow-up period ranged from 6 months to 15 years $[1,6,10,20]$.

\section{Surgical technique}

The surgical techniques in the included studies either used a to- tal or partial submuscular pocket for implant placement. However, the surgical techniques differed across studies. Pelle-Ceravolo et al. [1] described two groups of patients who underwent breast augmentation either using the Regnault technique, with inferomedial release of the pectoralis major muscle, or using their own muscle-splitting technique, in which a dual-plane technique was combined with a full-thickness muscle incision on a vertical line situated on the nipple projection. Spear et al. [6] used a dual-plane partial muscle coverage technique on all their consecutive patients, and Bracaglia et al. [20] used a tripleplane technique (Fig. 1). The triple-plane technique is described as a horizontally divided pectoralis major muscle at the level of the areola leading to muscle coverage of the implant in the upper and lower part, and subglandular coverage in the middle. Nigro and Blanchet [10] used a dual-plane technique for patients undergoing either direct-to-implant or 2-stage immediate breast reconstruction using acellular dermal matrix in the lower pole.

\section{Quality of the studies}

All the included studies had a clear description of the study

\section{Table 3. Definitions of breast animation deformity}

\begin{tabular}{|c|c|c|c|}
\hline Pelle-Ceravolo [1] & Spear [6] & Bracaglia [20] & Nigro [10] \\
\hline $\begin{array}{l}\text { Class I: non-existing or minimal } \\
\text { deformity }\end{array}$ & $\begin{array}{l}\text { Grade I: no distortion and unable to } \\
\text { discern whether the implant lies in } \\
\text { front of or behind the pectoralis } \\
\text { muscle }\end{array}$ & $\begin{array}{l}\text { Grade I: no distortion and unable to } \\
\text { discern whether the implant lies in } \\
\text { front of or behind the pectoralis } \\
\text { muscle }\end{array}$ & $\begin{array}{l}\text { "Twitching or movement of the upper } \\
\text { portion of the breast with certain } \\
\text { muscle movement of the arms or } \\
\text { chest" }\end{array}$ \\
\hline $\begin{array}{l}\text { Class II: moderate deformity with a } \\
\text { certain alteration of the breast shape } \\
\text { but with limited effect on the } \\
\text { aesthetic appearance of the breast }\end{array}$ & $\begin{array}{l}\text { Grade II: one is able to tell that the } \\
\text { implant is subpectoral, but there is } \\
\text { minimal distortion with an } \\
\text { aesthetically pleasing result }\end{array}$ & $\begin{array}{l}\text { Grade II: one is able to tell that the } \\
\text { implant is subpectoral, but there is } \\
\text { minimal distortion with an } \\
\text { aesthetically pleasing result }\end{array}$ & $\begin{array}{l}\text { If yes, how bothersome do you find it on } \\
\text { a scale } 1 \text { to } 10 \text { where } 1 \text { is not at all } \\
\text { and } 10 \text { being disabling? }\end{array}$ \\
\hline \multirow{2}{*}{$\begin{array}{l}\text { Class III: important and obvious } \\
\text { deformity that was definitely } \\
\text { aesthetically unacceptable }\end{array}$} & $\begin{array}{l}\text { Grade III: moderate distortion but still an } \\
\text { aesthetically acceptable result }\end{array}$ & $\begin{array}{l}\text { Grade III: moderate distortion but still an } \\
\text { aesthetically acceptable result }\end{array}$ & Converted to the following categories: \\
\hline & $\begin{array}{l}\text { Grade IV: severe distortion with an } \\
\text { unattractive result during muscle } \\
\text { contraction }\end{array}$ & $\begin{array}{l}\text { Grade IV: severe distortion with an } \\
\text { unattractive result during muscle } \\
\text { contraction }\end{array}$ & $\begin{array}{l}\text { None } \\
\text { Minimal: } 1-2.5 \\
\text { Mild: } 3-5 \\
\text { Moderate: } 5.5-7.5 \\
\text { Severe: } 8-10\end{array}$ \\
\hline
\end{tabular}

Table 4. Incidence rates of breast animation deformity

\begin{tabular}{|c|c|c|c|}
\hline Pelle-Ceravolo [1] & Spear [6] & Bracaglia [20] & Nigro [10] \\
\hline Group |a) & I: 22.5 (9/40) & I: 67 (351/524) & None: 24.4 (20/84) \\
\hline I: $69.9(1261 / 1,812)^{b)}$ & I: $62.5(25 / 40)$ & II: 29.7 (156/524) & Minimal/mild: 50 (41/84) \\
\hline II: $24.9(452 / 1,812)^{b)}$ & III: $10(4 / 40)$ & III: $3(17 / 524)$ & Moderate: 14.6 (12/84) \\
\hline III: $5.4(99 / 1,812)^{\text {b) }}$ & IV: $5(2 / 40)$ & IV: $0(0 / 524)$ & Severe: $11(9 / 84)$ \\
\hline Group $\|^{c)}$ & Self-evaluation & & \\
\hline I: $26.8(74 / 276)^{\mathrm{b})}$ & None-mild: 82 (56/69) & & \\
\hline II: $25.7(71 / 276)^{b)}$ & Moderate: 10 (7/69) & & \\
\hline III: $47.4(131 / 276)^{\text {b) }}$ & Severe: 7 (5/69) & & \\
\hline
\end{tabular}


sample. The participation rate was reported or possible to calculate in three of the four studies $[1,6,10]$. The minimum followup was 6 months for all studies, and health professionals were responsible for the data collection in three of the four studies $[1,6,20]$. BAD was clearly defined in all the included studies (Table 3). Two studies used a 4-point scale [6,20]; one study used a 3-point scale [1], and the remaining study used a 10-point scale that was later converted to a 4-point scale [10]. None of the studies examined whether their findings were reproducible. Two studies assessed the patient-reported evaluation of $\mathrm{BAD}$ using non-validated questionnaires $[6,10]$.

\section{Incidence of $\mathrm{BAD}$}

The total number of patients assessed for BAD was 996 in this review, not including the self-evaluating patients in the study by Spear et al. The median percentage of patients with some degree (mild, moderate, and severe) of BAD was 58\% (Table 4). The highest percentages were found in patients operated on with the Regnault technique or a dual-plane technique: Spear et al. found an incidence of 78\%, while Nigro and Blanchet reported an incidence of $76 \%$ and Pelle-Ceravolo et al. found an incidence of $73 \%$ in patients in whom the Regnault technique was used. The lowest incidence rates were found following the dual-plane muscle-splitting technique and the triple-plane technique: PelleCeravolo et al. reported a rate of $30 \%$ and Bracaglia et al. reported a rate of $33 \%$ for these techniques, respectively.

It is difficult to compare the findings regarding patients described as having a moderate degree of $\mathrm{BAD}$, because three of the included studies $[6,10,20]$ used a 4-point scale and the other study [1] used a 3-point scale. However, all these studies specified a "severe" $\mathrm{BAD}$ category. The incidence of severe $\mathrm{BAD}$ was $47 \%$ following operations using the Regnault technique, and 5\% and $11 \%$ following dual-plane augmentation and reconstruction, respectively. After the dual-plane muscle-splitting technique, severe $\mathrm{BAD}$ occurred in $5 \%$ of patients, whereas it occurred in $0 \%$ of patients in whom the triple-plane technique was used.

\section{DISCUSSION}

Four different surgical methods and types of pectoralis major muscle involvement were presented and compared: (1) the Regnault technique; (2) dual-plane partial muscle coverage; (3) the dual-plane technique in combination with muscle-splitting and partial muscle coverage; and (4) the triple-plane technique with partial muscle coverage (Fig. 1). The percentage of patients with BAD varied between $30 \%$ and $78 \%$, with a median of $58 \%$. Upon first impression, the data seem to indicate that there was no meaningful difference in the incidence of $\mathrm{BAD}$ between the Reg- nault technique and the dual-plane technique, whereas the degree of $\mathrm{BAD}$ was lower following the muscle-splitting and tripleplane techniques. When examining the degree of severe $\mathrm{BAD}$, there was a clear trend for the incidence of severe $\mathrm{BAD}$ to increase with the degree of muscle coverage, as the use of the Regnault technique by Pelle-Ceravolo et al. resulted in an incidence of severe $\mathrm{BAD}$ of $47 \%$. In contrast, Nigro and Blanchet [10] and Spear et al. [6] reported that severe BAD occurred in 5\% and $11 \%$ of patients following dual-plane augmentation and reconstruction, respectively; Pelle-Ceravolo et al. reported that severe $\mathrm{BAD}$ occurred in $5 \%$ of patients in whom the dual-plane musclesplitting technique was used; and Bracaglia et al. reported severe $\mathrm{BAD}$ in $0 \%$ of their patients in whom the triple-plane technique was used. We postulate that the likelihood of $\mathrm{BAD}$ varies with the degree of muscle coverage/involvement and that the incidence of $\mathrm{BAD}$ can be expected to be close to $0 \%$ when there is no muscle coverage. However, this conclusion cannot be firmly made on the basis of this study due to the lack of data of sufficient quality for comparison, and this issue remains to be elucidated.

Thus, the data seem to show a clear association between the degree of muscle coverage and the degree of $\mathrm{BAD}$, even though the grading systems are not directly comparable. Pelle-Ceravolo et al. used a 3-point scale to evaluate their own technique in comparison to the Regnault technique, whereas the three other studies used 4-point scales for their evaluation. This could imply that the incidence of moderate to severe $\mathrm{BAD}$ was overestimated in the study by Pelle-Ceravolo et al., since a larger proportion of their patients could have been classified in the severe category. Furthermore, the ability to compare the surgical technique developed by Pelle-Ceravolo et al. with the Regnault technique is limited, as the larger number of patients who underwent surgery using their technique (302 patients vs. 46 patients) might have lowered the incidence of severe $\mathrm{BAD}$.

The examinations of BAD should be compared with caution. The degree of $\mathrm{BAD}$ was not evaluated using the same scale, and the evaluation was performed in different ways. Pelle-Ceravolo et al. performed a physical exam for all their patients, whereas Spear et al. and Bracaglia et al. used photographs to evaluate the degree of $\mathrm{BAD}$. The classification of $\mathrm{BAD}$ differed among studies. Pelle-Ceravolo et al. used three examiners for each patient: a plastic surgeon, a nurse, and the patient. Spear et al. used a group of plastic surgery residents, and Bracaglia et al. used three experienced plastic surgeons. This combination of different observers, with different levels of experience and expertise, could affect the quality and comparability of the evaluations.

In two of the studies, by Nigro and Blanchet [10] and Spear et al. [6], the degree of $\mathrm{BAD}$ was evaluated by the patients using questionnaires. Spear et al. reported a remarkable similarity in 
the assessments of $\mathrm{BAD}$ using the photo evaluations and the questionnaires.

The patient questionnaires used in the study by Spear et al. are interesting in that none of the patients experienced any inconvenience in relation to daily activities, but $24 \%$ and $19 \%$ stated that they were affected when lifting weights or exercising in general. When asked if they would choose the retropectoral implant placement again, $70 \%$ would, $28 \%$ were unsure, and $3 \%$ would not choose it again. However, we cannot know if these data are representative of the entire cohort, since the response rate to the questionnaire was rather low (35\%; 69 of 195). This implies a major risk of selection bias; in particular, it is possible that the patients who felt most positively about their outcomes might have replied, while those who were less satisfied did not.

In the most recent study by Nigro and Blanchet [10], 84 of 108 patients (78\%) replied to questionnaires regarding a self-assessment of the degree of $\mathrm{BAD}$ and how bothersome $\mathrm{BAD}$ was to their daily activities. Three-quarters (74\%) of patients reported experiencing some degree of $\mathrm{BAD}$. They did not find a significant difference in the degree of $\mathrm{BAD}$ between athletic and non-athletic women. This finding is counterintuitive, as one would expect that $\mathrm{BAD}$ would affect athletic women the most, which has also been suggested in two studies that found that athletic women were more prone to suffer from $\operatorname{BAD}[6,14]$.

The follow-up differed among studies, ranging from 6 months to 15 years. This may have affected the results, as we do not know whether $\mathrm{BAD}$ improves or worsens with time.

We expected to be able to compare the above-mentioned techniques for implant-based breast augmentation and breast reconstruction to prepectoral implant placement, since the number of papers describing prepectoral implant placement to avoid $\mathrm{BAD}$ are increasing at a rapid pace. Unfortunately, several studies were not included in this review because $\mathrm{BAD}$ was not clearly defined or described, or because the Results section did not contain any data regarding the assessment of $\mathrm{BAD}[2,3,5,11,14-16,18,21$ $27,29,30]$. The selection process is presented in the PRISMA flowchart in Fig. 1.

It is challenging to compare the four included studies and to interpret the reported incidence rates due to differences in the assessment of $\mathrm{BAD}$ and because the authors did not examine whether their results were reproducible by conducting an interor intra-rater reliability study.

The most important question regarding this issue is whether patients perceive $\mathrm{BAD}$ as a problem and how it affects their quality of life. A recent study by Becker and Fregosi [5] investigated this question. They contacted 25 women who had undergone submuscular breast reconstruction and found that $100 \%$ experienced $\mathrm{BAD}$ and $80 \%$ were bothered by it. Although the study population was small, it is noteworthy that all the patients experienced $\mathrm{BAD}$.

To evaluate this condition, it is imperative that assessments are consistently performed in a reproducible manner to enable a standardized comparison of the results. We need a standardized grading scale for $\mathrm{BAD}$ that could be used to assess the degree of $\mathrm{BAD}$ in both augmented and reconstructed populations. The optimal assessment would be based on a clinical evaluation in an outpatient clinic. The second-best option is to assess BAD by watching videos of the patients. This may be advantageous, since the videos can be used for inter- and intra-rater reliability assessments to test the reproducibility of the scale. Still photos

\section{Fig. 3. Woman with subpectoral implant placement}

The two photographs demonstrate (A) no breast animation deformity at rest and (B) a visible deformity during muscle contraction.
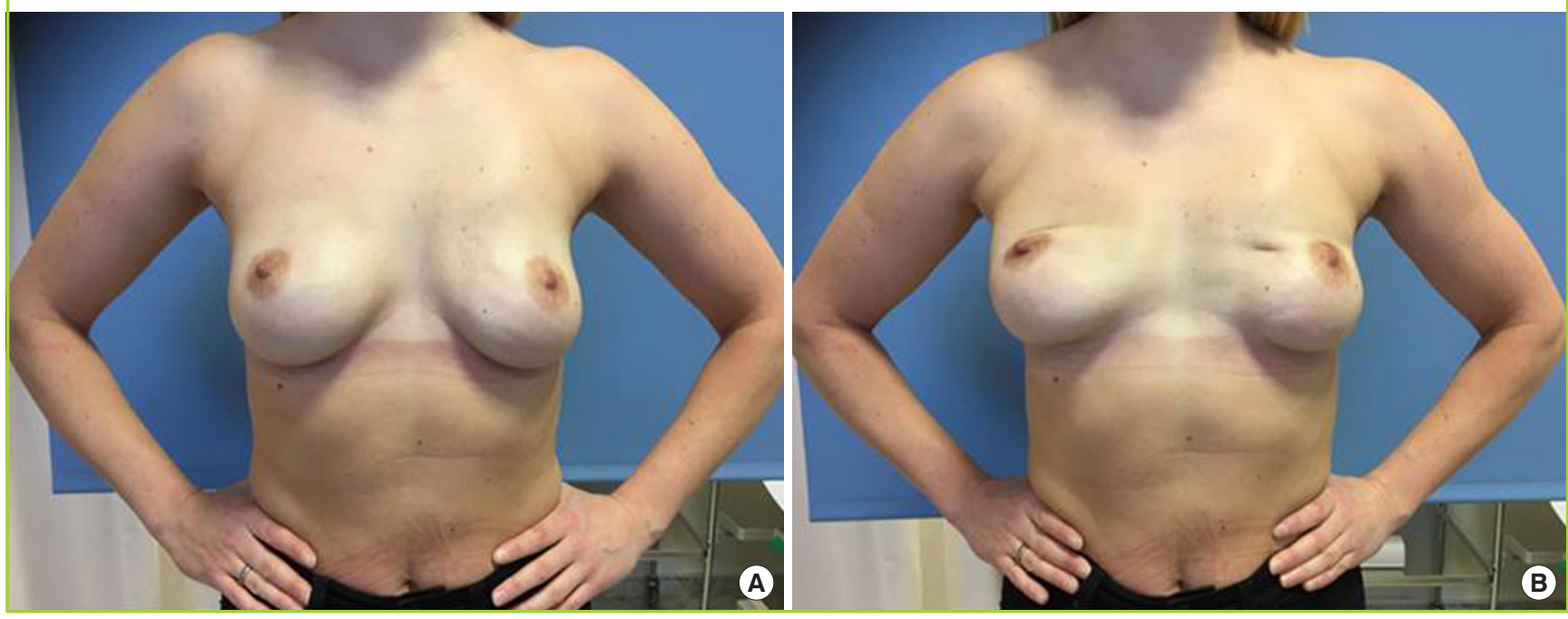
can be used as a tool for documenting the dynamic phenomenon of $\mathrm{BAD}$ if images are taken with the patient in a relaxed position and when activating the major pectoral muscle for comparison (Fig. 3).

Furthermore, it is necessary to demonstrate that the trend towards prepectoral implant placement, especially in breast reconstruction, can lead to the same level of aesthetic and functional results as submuscular implant placement in the long term. Prepectoral placement of implants might improve $\mathrm{BAD}$, but it may cause significantly more capsular contracture [17]. However, we will have to wait for at least 5 years before we will get any indication of whether this is true.

Assessment of quality of life and patient-related outcome measures in patients diagnosed with $\mathrm{BAD}$ is just as important as grading the severity of $\mathrm{BAD}$ itself. We may not need to treat $\mathrm{BAD}$ or to change our reconstructive techniques if $\mathrm{BAD}$ does not influence quality of life and patient-related outcome measures. We need more studies that assess BAD using quality of life and patient-related outcome measures, as well as a standardized and reproducible grading scale, to gain insight into these issues.

\section{CONCLUSION}

The degree of $\mathrm{BAD}$ seems to be proportional to the degree of muscle involvement in implant-based breast augmentation and reconstruction. The highest incidence of severe $\mathrm{BAD}$ was observed following the Regnault technique and the lowest incidence following the triple-plane surgical technique. A standardized reproducible grading scale is needed to evaluate the degree of $\mathrm{BAD}$ in a way that would allow comparison across studies, and studies of quality of life and patient-related outcome measures are needed to determine whether $\mathrm{BAD}$ is perceived as a problem by patients.

\section{NOTES}

\section{Conflict of interest}

No potential conflict of interest relevant to this article was reported.

\section{Ethical approval}

The study was approved by the Regional Committees on Health Research Ethics for Southern Denmark (S-20160160) and performed in accordance with the principles of the Declaration of Helsinki. Written informed consents were obtained.

\section{Patient consent}

The patient provided written informed consent for the publication and the use of her images.

\section{ORCID}

Diana Lydia Dyrberg https://orcid.org/0000-0002-1537-7703

Jørn Bo Thomsen https://orcid.org/0000-0002-7368-6133

\section{Supplementary Material}

Supplemental Table 1. Search histories

Supplemental data can be found at:

https://doi.org/10.5999/aps.2018.00479

\section{REFERENCES}

1. Pelle-Ceravolo M, Del Vescovo A, Bertozzi E, et al. A technique to decrease breast shape deformity during muscle contraction in submuscular augmentation mammaplasty. Aesthetic Plast Surg 2004;28:288-94.

2. Strasser EJ. Results of subglandular versus subpectoral augmentation over time: one surgeon's observations. Aesthet Surg J 2006;26:45-50.

3. Lesavoy MA, Trussler AP, Dickinson BP. Difficulties with subpectoral augmentation mammaplasty and its correction: the role of subglandular site change in revision aesthetic breast surgery. Plast Reconstr Surg 2010;125:363-71.

4. Sbitany H, Piper M, Lentz R. Prepectoral breast reconstruction: a safe alternative to submuscular prosthetic reconstruction following nipple-sparing mastectomy. Plast Reconstr Surg 2017; 140:432-43.

5. Becker H, Fregosi N. the impact of animation deformity on quality of life in post-mastectomy reconstruction patients. Aesthet Surg J 2017;37:531-6.

6. Spear SL, Schwartz J, Dayan JH, et al. Outcome assessment of breast distortion following submuscular breast augmentation. Aesthetic Plast Surg 2009;33:44-8.

7. Becker H, Lind JG 2nd, Hopkins EG. Immediate implantbased prepectoral breast reconstruction using a vertical incision. Plast Reconstr Surg Glob Open 2015;3:e412.

8. Henriksen TF, Fryzek JP, Holmich LR, et al. Surgical intervention and capsular contracture after breast augmentation: a prospective study of risk factors. Ann Plast Surg 2005;54: 343-51.

9. Spear SL, Bulan EJ, Venturi ML. Breast augmentation. Plast Reconstr Surg 2006;118(7 Suppl):188S-196S.

10. Nigro LC, Blanchet NP. Animation deformity in postmastectomy implant-based reconstruction. Plast Reconstr Surg 
Glob Open 2017;5:e1407.

11. Reitsamer R, Peintinger F. Prepectoral implant placement and complete coverage with porcine acellular dermal matrix: a new technique for direct-to-implant breast reconstruction after nipple-sparing mastectomy. J Plast Reconstr Aesthet Surg 2015;68:162-7.

12. Wallace MS, Wallace AM, Lee J, et al. Pain after breast surgery: a survey of 282 women. Pain 1996;66:195-205.

13. Figus A, Mazzocchi M, Dessy LA, et al. Treatment of muscular contraction deformities with botulinum toxin type A after latissimus dorsi flap and sub-pectoral implant breast reconstruction. J Plast Reconstr Aesthet Surg 2009;62:86975.

14. Kobraei EM, Cauley R, Gadd M, et al. Avoiding breast animation deformity with pectoralis-sparing subcutaneous direct-to-implant breast reconstruction. Plast Reconstr Surg Glob Open 2016;4:e708.

15. Khan UD. Dynamic breasts: a common complication following partial submuscular augmentation and its correction using the muscle-splitting biplane technique. Aesthetic Plast Surg 2009;33:353-60.

16. Hammond DC, Schmitt WP, O'Connor EA. Treatment of breast animation deformity in implant-based reconstruction with pocket change to the subcutaneous position. Plast Reconstr Surg 2015;135:1540-4.

17. Egeberg A, Sorensen JA. The impact of breast implant location on the risk of capsular contraction. Ann Plast Surg 2016;77:255-9.

18. Banbury J, Yetman R, Lucas A, et al. Prospective analysis of the outcome of subpectoral breast augmentation: sensory changes, muscle function, and body image. Plast Reconstr Surg 2004;113:701-7.

19. Liberati A, Altman DG, Tetzlaff J, et al. The PRISMA statement for reporting systematic reviews and meta-analyses of studies that evaluate health care interventions: explanation and elaboration.J Clin Epidemiol 2009;62:e1-34.
20. Bracaglia R, Tambasco D, Gentileschi S, et al. Triple-plane technique for breast augmentation: solving animation deformities. Aesthetic Plast Surg 2013;37:715-8.

21. Graf RM, Bernardes A, Rippel R, et al. Subfascial breast implant: a new procedure. Plast Reconstr Surg 2003;111:9048.

22. Goes JC, Landecker A. Optimizing outcomes in breast augmentation: seven years of experience with the subfascial plane. Aesthetic Plast Surg 2003;27:178-84.

23. Siclovan HR, Jomah JA. Advantages and outcomes in subfascial breast augmentation: a two-year review of experience. Aesthetic Plast Surg 2008;32:426-31.

24. Lang Stumpfle R, Figueras Pereira-Lima L, Alves Valiati A, et al. Transaxillary muscle-splitting breast augmentation: experience with 160 cases. Aesthetic Plast Surg 2012;36:3438.

25. Stoff-Khalili MA, Scholze R, Morgan WR, et al. Subfascial periareolar augmentation mammaplasty. Plast Reconstr Surg 2004;114:1280-8.

26. Pereira LH, Sterodimas A. Transaxillary breast augmentation: a prospective comparison of subglandular, subfascial, and submuscular implant insertion. Aesthetic Plast Surg 2009;33:752-9.

27. Khan UD. Muscle-splitting breast augmentation: a new pocket in a different plane. Aesthetic Plast Surg 2007;31: 553-8.

28. Gabriel A, Sigalove S, Sigalove NM, et al. Prepectoral revision breast reconstruction for treatment of implant-associated animation deformity: a review of 102 reconstructions. Aesthet Surg J 2018;38:519-26.

29. Baxter RA. Subfascial breast augmentation: theme and variations. Aesthet Surg J 2005;25:447-53.

30. Khan UD. High transverse capsuloplasty for the correction of malpositioned implants following augmentation mammoplasty in partial submuscular plane. Aesthetic Plast Surg 2012;36:590-9. 